Revista Destaques Acadêmicos, Lajeado, v. 11, n. 2, 2019. ISSN 2176-3070

DOI: http://dx.doi.org/10.22410/issn.2176-3070.v11i2a2019.1926

http://www.univates.br/revistas

\title{
OS IMPACTOS SOCIAIS E HUMANOS ASSOCIADOS A ACIDENTES COM MOTOCICLISTAS: UMA REVISÃO INTEGRATIVA
}

\author{
Lilianete Fagundes ${ }^{1}$, Aurinez Rospide Schmitz ${ }^{2}$
}

\begin{abstract}
Resumo: O objetivo deste trabalho é realizar uma revisão Integrativa, a fim de apresentar estatísticas do estado do Rio Grande do Sul e avaliar os impactos da depressão associados a acidentes com motociclistas. Este artigo é resultado de uma pesquisa qualitativa, a partir de uma revisão sistemática. A coleta de dados foi realizada por meio de consulta a publicações de autores de referência na área e posterior leitura crítica dos títulos e dos resumos. Como critérios de inclusão das referências bibliográficas, foram utilizados artigos científicos publicados em idioma Português, nas bases de dados Scientific Electronic Library Online (SCIELO), PUBMED e Literatura Latino Americana em Ciências da Saúde (LILACS). Como descritores para busca bibliográfica foram utilizados: "Motocicleta" e "Acidente". Nos dias atuais o fator "tempo" e a rapidez que este indivíduo irá conduzir seu veículo, independente se o uso é pessoal ou a trabalho, é considerado por muitos como "mais precioso" que sua própria vida. Fator este que o leva a conduzir seu veículo além da velocidade permitida, por necessidade ou não, comportando-se de maneira a não identificar o estabelecido pela lei.Sugerese que novos estudos sejam realizados com esses instrumentos a fim de aprimorar as suas qualidades, por meio das adaptações necessárias, ou com a construção de outras medidas que avaliem esta realidade.
\end{abstract}

Palavras-chave: Motocicleta. Acidente. Depressão. Psicologia do Trânsito.

\section{INTRODUÇÃO}

Conforme o Código de Trânsito Brasileiro, o trânsito pode ser definido como o deslocamento de pessoas pelas vias de circulação, parada, estacionamento e operação de carga e descarga (BRASIL, 1997, Artigo $1^{\circ}, \S 1^{\circ}$ ).

A produção de veículos cresceu assustadoramente no mundo, trazendo novos rumos a legislação de trânsito brasileira em todos os aspectos. No início

1 Psicóloga. Estudante do curso de Pós-Graduação de Psicologia do Trânsito da Universidade do Vale do Taquari (Univates).

2 Psicóloga e Docente da Universidade do Vale do Taquari (Univates). 
do século $X X$, os primeiros automóveis e caminhões começaram a circular no Brasil. (SILVA; GÜNTHER, 2009)

De acordo com Rosestraten e Dotta (1986), dirigir com atenção e cuidado reduz os acidentes de trânsito, tendo em vista que o fator humano é a principal causa de acidentes. Investir em educação no trânsito, comportamento seguro e legislação, são importantes pois atuam preventivamente para reduzir os acidentes.

A motocicleta tem sido uma opção de muitas pessoas por ter preço acessível, baixo custo de manutenção e de fácil locomoção, entretanto, o motorista fica vulnerável por estar exposto e mais propenso a ter acidentes graves ou fatais (FRANZON et. al, 2013). Todos os anos, aproximadamente 1,3 milhões de pessoas morrem vítimas da imprudência ao volante. Segundo a Organização Mundial de Saúde (2016), dos sobreviventes, cerca de 50 milhões vivem com sequelas. O levantamento foi feito em 2009, em 178 países. Além disso, o trânsito é a nona maior causa de mortes, do planeta.

\section{METODOLOGIA}

Este artigo é resultado de uma pesquisa qualitativa, a partir de uma revisão sistemática. A coleta de dados foi realizada por meio de consulta a publicações de autores de referência na área e posterior leitura crítica dos títulos e dos resumos. Como critérios de inclusão das referências bibliográficas, foram utilizados artigos científicos publicados nas bases de dados Scientific Electronic Library Online (SCIELO), PUBMED e Literatura Latino Americana em Ciências da Saúde (LILACS). Como descritores para busca bibliográfica foram utilizados: "Motocicleta" e "Acidente". Os resultados desta etapa estão expostos no Quadro 1:

Quadro 1 - Publicações disponíveis sem filtros, conforme os descritores nas bases de dados.

\begin{tabular}{|c|c|c|}
\hline $\begin{array}{c}\text { Base } \\
\text { De dados }\end{array}$ & Motocicleta & $\begin{array}{c}\text { Motocicleta } \\
\text { AND } \\
\text { Acidente }\end{array}$ \\
\hline SCIELO & 14 & 4 \\
\hline BVS & 0 & 0 \\
\hline LILACS & 0 & 0 \\
\hline TOTAL & & \\
\hline
\end{tabular}

Fonte: Autoras, 2018.

Após construção do quadro, foram utilizados como critérios de inclusão para o estudo os critérios: ano de publicação entre 2013 e 2018; artigos 
disponíveis na íntegra. É importante ressaltar, que em algumas bases de dados, não foram encontrados artigos com estes descritores, ou estavam duplicados. Dois artigos foram excluídos devido ao ano ser inferior a 5 anos. Desta forma, para análise final foram utilizados 2 artigos (Quadro 2).

Quadro 2 - Títulos e autores dos artigos que compõem o trabalho

\begin{tabular}{|c|c|l|}
\hline $\mathrm{N}^{\mathrm{o}}$ artigo & \multicolumn{1}{|c|}{ Título } & \multicolumn{1}{c|}{ Autores } \\
\hline 1 & $\begin{array}{c}\text { Masculinidades em Trânsito: } \\
\text { Processos Identitários de Motoboys } \\
\text { em Belo Horizonte - MG }\end{array}$ & $\begin{array}{l}\text { MIRANDA, Gregório Ribeiro } \\
\text { de; NASCIMENTO, Adriano } \\
\text { Roberto Afonso do. }\end{array}$ \\
\hline 2 & $\begin{array}{c}\text { Characteristics of motorcyclists } \\
\text { involved in acidentes between } \\
\text { motorcycles and automobiles }\end{array}$ & $\begin{array}{l}\text { OLIVEIRA, Amanda Lima } \\
\text { de; PETROIANU, Andy; } \\
\text { GONÇALVES, Dafne Maria } \\
\text { Villar; PEREIRA, Gisele } \\
\text { Araújo; ALBERTI, Luiz } \\
\text { Ronaldo. }\end{array}$ \\
\hline
\end{tabular}

Fonte: Autoras, 2018.

\section{ACIDENTES COM MOTOCICLISTAS E SUAS CAUSAS}

Segundo Franzon e colaboradores (2013), a calma e consciência do motorista é o fator mais importante pois $95 \%$ dos acidentes poderiam ser evitados pelo motociclista. A velocidade em alguns casos está relacionada com o relacionamento social, principalmente, tratando-se de jovens motoristas, onde a velocidade e manobras perigosas estão relacionadas com popularidade. $\mathrm{O}$ consumo de bebidas alcoólicas é outro fator relevante, pois o álcool cria uma realidade diferente da atual, deixando o motorista corajoso a cometer imprudências.

A velocidade também está relacionada à pressa, alguns motociclistas precisam chegar com horário marcado, é o caso dos profissionais, onde excedendo a velocidade, acabam colocando suas vidas e de outras pessoas em risco (HOFFMANN et al, 2003).

Muitas pessoas com depressão utilizam veículos e normalmente desconhecem a incidência desta alteração nas capacidades psicofísicas necessárias para conduzir. Dentre as alterações que os estudos destacam estão a diminuição da atenção, um constante risco para sofrer acidente, a tendência suicida, fazendo com que utilizem o veículo como meio de acabar com a sua vida, alterações do sono que geram um conjunto de disfunções ao volante, alterações na capacidade de tomada de decisão, alterações sensoriais, em especial à diminuição do campo visual. Aos efeitos prejudiciais da depressão para a atividade de conduzir um veículo, somam-se também aqueles derivados 
do álcool e psicofármacos em pessoas depressivas (HOFFMANN; LEGAL, 2003).

De acordo com o trabalho realizado por Oliveira e colaboradores (2015) dos 100 acidentados, 91 eram homens e 9 eram mulheres com idade de 16 a 79 anos. $83 \%$ utilizam a motocicleta como meio de transporte, $7 \%$ para trabalho e $10 \%$ para lazer. Em relação ao estudo $47 \%$ possuem ensino médio completo. $68,3 \%$ com habilitação com categoria A, mais de 1 ano; $67 \%$ menos 1 ano.

Desta forma, identifica-se a predominância do sexo masculino nos acidentes envolvendo motocicletas, o que repercute diretamente na perda da força do trabalho que traz sequelas para a produtividade do País e para as famílias. Outro aspecto a considerar diz respeito ao tempo de habilitação dos condutores envolvidos em acidentes, menos de 1 ano, o que pode indicar a necessidade de aprofundar a qualificação para a habilitação.

Já, o estudo realizado pelo DETRAN/RS (2017), nos anos de 2010 a 2016 apontam 4.382 acidentes com morte com o envolvimento de motocicletas, constatando que $23 \%$ não eram habilitados, fato importante a ser considerado na medida em que estes condutores não passam pelos critérios de avaliação exigidos que analisam suas habilidades técnicas e condições emocionais para a habilitação. Entre os 2.901 motoristas de motocicletas envolvidos em acidentes fatais, $76 \%$ não tinham habilitação profissional. O levantamento constatou que maior parte dos acidentes acontecem com motoristas habilitados a mais de um ano, sendo a maioria com idades entre 20 e 34 anos, totalizando $61,7 \%$. As cidades que apresentam maior índice de acidentes fatais no Rio Grande do Sul são: Pelotas (56\%), Novo Hamburgo (50\%), Santa Cruz do Sul (49\%), Canoas (48\%), Camaquã, Alvorada e Sapiranga (46\%) e Uruguaiana (45\%).

A Psicologia do trânsito é responsável por avaliar o comportamento de todos os participantes do trânsito das rodovias e das redes viárias urbanas, para isto a teoria da propensão aos acidentes, é uma tendência em disciplinas relacionadas ao trânsito no mundo inteiro, inclusive no Brasil (ROZESTRATEN, 1981).

Para Pinto, (2013) a psicologia trabalha, também com a percepção de risco, para auxiliar na compreensão do comportamento do motorista no trânsito, o autor, cita duas teorias: "Causal Accident Theory" que afirma que para prevenir os acidentes é preciso encontrar as causas do acidente. Os estudos encontrados sobre esta teoria afirmam que maior parte dos acidentes não está relacionado a apenas um fator contribuinte, e que os fatores humanos são a principal causa dos acidentes de trânsito. A Epidemiological Theory afirma que os acidentes de trânsito são resultado de características da via. A teoria busca por soluções para os acidentes modificando os componentes técnicos do sistema de transporte, diminuindo o índice de acidentes. 


\section{CONCLUSÃO}

Dentre os trabalhos analisados, há prevalência de estudos empíricos, focados principalmente na investigação da personalidade e atenção.

Nos dias atuais o fator "tempo" e a rapidez que este indivíduo irá conduzir seu veículo, independente se o uso é pessoal ou a trabalho, é considerado por muitos como "mais precioso" que sua própria vida. Fator este que o leva a conduzir seu veículo além da velocidade permitida, por necessidade ou não, comportando-se de maneira a não identificar o estabelecido pela lei. Sugere-se que novos estudos sejam realizados com instrumentos de avaliação psicológica a fim de aprimorar as suas qualidades, por meio das adaptações necessárias, ou com a construção de outras medidas que avaliem esta realidade, especialmente relacionados aos motociclistas.

Neste artigo foram apresentados alguns aspectos que devem ser considerados no complexo tema que envolve acidentalidade e motocicletas. Sugere-se que este tema seja aprofundado devido sua relevância e impacto individual e de âmbito social.

\section{REFERÊNCIAS}

DETRAN - Departamento de Trânsito do Rio Grande do Sul.Um terço dos motociclistasenvolvidosemacidentesfataisnãoestavahabilitado. 2017. Acessoem: <http://www.detran.rs.gov.br/conteudo/46273/um-terco-dos-motociclistasenvolvidos-em-acidentes-fatais-nao-estava-habilitado>Acessoem 01 jul. 2018.

FRANZON et. al, 2013: Akrópolis, Umuarama, v. 21, n. 1, p. 43-54, jan./jun. 2013.

HOFFMANN, M. H.; CRUZ, R. M.; ALCHIERI; J. C. Comportamento humano no trânsito. Casa do Psicólogo, p. 413, 2003.

MIRANDA, G. R. de; NASCIMENTO, A. R. A. do.Masculinidades em Trânsito: Processos Identitários de Motoboys em Belo Horizonte - MG. Temas psicol. vol.26 no.2 Ribeirão Preto abr./jun. 2018.

OLIVEIRA, A. L. de; PETROIANU, A.; GONÇALVES, D. M. V.;

PEREIRA, G. A.; ALBERTI, L.R.Characteristicsofmotorcyclistsinvolved in accidentsbetweenmotorcyclesandautomobiles. Rev. Assoc. Med. Bras. vol.61 no.1 São Paulo Jan./Feb. 2015.

OMS - Organização Mundial da Saúde. Acidentes de trânsito. Disponível em: $<$ https://www.paho.org/bra/index.php?option=com_content\&view=article\&id=514 7:acidentes-de-transito-folha-informativa\&Itemid=779>.Acesso em: 01 jun. 2018.

PINTO,P. V. H.Avaliação do comportamento de risco de Motociclistas no cenário brasileiro.Universidade De Brasília, 2013. 
ROZESTRATEN, R. J. A. Psicologia Social e o trânsito. Psicologia: ciência e profissão, v.6 n.2 p. 22-23, 1986.

SILVA, Fábio Henrique Vieira de Cristo e; GUNTHER, Hartmut. Psicologia do trânsito no Brasil: de onde veio e para onde caminha?. Temas psicol., Ribeirão Preto, v. 17, n. 1, p. 163-175, 2009. Disponível em <http:/ / pepsic.bvsalud.org/scielo. php?script=sci_arttext\&pid=S1413-389X2009000100014\&lng=pt\&nrm=iso $>$. acessos em 14 abr. 2018. 